\title{
Stage V Kidney Wilms Tumor
}

National Cancer Institute

\section{Source}

National Cancer Institute. Stage V Kidney Wilms Tumor. NCI Thesaurus. Code C7844.

Wilms tumor that affects both kidneys at the same time. The tumor in each kidney is staged separately (National Wilms Tumor Study Group Staging System) 